\title{
Percutaneous Mitral Balloon Valvuloplasty: Surviving the Test of Time
}

\author{
Igor F. Palacios ${ }^{1}$, Guilherme V. Silva ${ }^{2}$
}

C ardiovascular disease remains the most important disease of the Western world. As such, many strides against cardiovascular disease have been made in recent decades, particularly when considering coronary artery disease. Cardiologists have gone from an era of "watchful waiting" of patients with acute myocardial infarction and severe coronary disease to aperiod of surgical revascularisation, which finally evolved to the new percutaneous interventional era, culminating with drug-eluting stents. Thus, the new subspecialty of interventional cardiology was born.

\section{See page 253}

Conquering structural heart disease has long been an interventional cardiologist's dream. The treatment for valvular heart disease perfectly fits the interventionist's drive. It has progressed from "watchful waiting" to surgical correction, and finally to innovative, and revolutionary, and minimally invasive percutaneous procedures. Percutaneous pulmonary balloon valvuloplasty was the first percutaneous treatment for valvular heart disease. ${ }^{1}$ A close second, percutaneous mitral balloon valvuloplasty can certainly be considered one of the most innovative percutaneous procedures, and it has led the way to a new subspecialty: structural heart disease percutaneous intervention.

As with any new technological innovation, in the beginning, there was close scrutiny and opposition to change the status quo: surgical mitral commissurotomy. Several studies have compared the immediate and early follow-up results of percutaneous mitral balloon valvuloplasty versus closed surgical commissurotomy and demonstrated that there was either superior outcome from percutaneous mitral balloon valvuloplasty ${ }^{2,3}$ or no significant differences between both techniques in ideal patients for these procedures. ${ }^{4-6}$ The evaluation of candidates for percutaneous mitral balloon valvuloplasty requires a precise assessment of both valve morphology and function for pre-procedure decision-making, as well as patient follow-up. Patient selection is essential for predicting the immediate outcome and follow-up results of percutaneous mitral balloon valvuloplasty. Aguiar Filho et al., ${ }^{7}$ in this edition of the Revista Brasileira de Cardiologia Invasiva, highlight this fundamental issue of patient selection, as the mean Wilkins score of the current population was 7.6 and only 32 patients $(16 \%)$ had a score $>8$. This is no surprise, given the known expertise and experience of this group of clinical investigators, with distinct surgeons such as Esteves and Abizaid, who have been involved in developing and perfecting percutaneous valve therapy since the early days.

It is well defined that other patient-related factors, such as older age, presence of atrial fibrillation and pre-procedural mitral regurgitation can negatively affect percutaneous mitral balloon valvuloplasty outcomes. Differences in age and valve morphology may account for the lower survival and event-free survival of percutaneous mitral balloon valvuloplasty series from the United States and Europe. For example, in the series from the Massachusetts General Hospital, 497 patients with echocardiographic scores $\leq 8$ and a mean age of $51 \pm 14$ years had an $85 \%$ survival and a $45 \%$ eventfree survival at the end of an eight-year follow-up. In contrast, 237 patients with echocardiographic scores $>8$ and a mean age of $63 \pm 14$ years had a 55\% eight-year survival, and only $20 \%$ of them were free of combined events at the end of the eight-year follow-up. Regarding the current Brazilian series, the authors report a very long-term follow-up after percutaneous mitral balloon valvuloplasty in a group of young patients (mean age of 32 years), with the great majority in normal sinus rhythm and mitral regurgitation present in only $13 \%$ of the patients followed. The reported $85 \%$ probability of being free from restenosis at five years likely reflects the characteristics of the patient population. However, at ten and 20 years, the probability of being free from restenosis declined to $60 \%$ and $36 \%$, respectively; 25

\footnotetext{
1 Director of Interventional Cardiology at Massachusetts General Hospital. Associate Professor of Medicine at Harvard Medical School. Boston, MA, USA.

2 Structural Heart Disease Fellow at Massachusetts General Hospital. Boston, MA, USA.
}

\author{
Correspondence to: Igor F. Palacios. Massachusetts General Hospital - 55 \\ Fruit Street - Boston, MA, USA - 02114. \\ E-mail: ipalacios@partners.org
}

Received on: 10/9/2012 • Accepted on: 10/10/2012 
patients required a second percutaneous mitral balloon valvuloplasty, and 27 patients underwent surgery after restenosis was diagnosed. This confirms that percutaneous mitral balloon valvuloplasty should be the first-line treatment for rheumatic mitral stenosis, with the understanding that, in the long run, some patients will require a second percutaneous mitral balloon valvuloplasty or mitral valve surgery.

Lastly, there is no singular percutaneous mitral balIoon valvuloplasty technique. In the current report, the great majority of the patients underwent the antegrade double-balloon technique. Most of the percutaneous mitral balloon valvuloplasty techniques require transseptal left heart catheterisation and an antegrade approach. There is controversy as to whether the double-balloon technique versus the Inoue technique of percutaneous mitral balloon valvuloplasty provides superior immediate and long-term results. Compared with the Inoue technique, the double-balloon technique results in a larger mitral valve area and a lesser degree of severe mitral regurgitation after percutaneous mitral balloon valvuloplasty, particularly in patients with echocardiographic scores $\leq 8$. However, despite the difference in immediate outcome between both techniques, there are no significant differences in survival, event-free survival, or restenosis over long-term clinical follow-up.

Percutaneous balloon mitral valvuloplasty has definitely survived the test of time. Aguiar Fillho et al. ${ }^{7}$ once more confirmed the success of this groundbreaking structural percutaneous intervention as a first-line treatment for rheumatic mitral stenosis. The historical and well-established success of percutaneous mitral balloon valvuloplasty should inspire the new generation of structural heart disease interventionists to further innovate and change the landscape of valvular heart disease treatment once and for all.

\section{CONFLICT OF INTEREST}

The authors declare no conflicts of interest.

\section{REFERENCES}

1. Kan JS, White RI Jr, Mitchell SE, Gardner TJ. Percutaneous balloon valvuloplasty: a new method for treating congenital pulmonary-valve stenosis. N Engl J Med. 1982;307(9):540-2.

2. Patel JJ, Sharma D, Mitha AS, Blyth D, Hassen F, Le Roux BT, et al. Balloon valvuloplasty versus closed commissurotomy for pliable mitral stenosis: a prospective hemodynamic study. J Am Coll Cardiol. 1991;18(5):1318-22.

3. Shrivastava S, Mathur A, Dev V, Saxena A, Venugopal P, SampathKumar A. Comparison of immediate hemodynamic response of closed mitral commissurotomy, single-balloon, and double-balloon mitral valvuloplasty in rheumatic mitral stenosis. J Thorac Cardiovasc Surg. 1992;104(5):1264-7.

4. Turi ZG, Reyes VP, Raju BS, Raju AR, Kumard N, Rajagopal P, et al. Percutaneous balloon versus surgical closed commissurotomy for mitral stenosis: a prospective, randomized trial. Circulation. 1991;83(4):1179-85.

5. Arora R, Nair M, Kalra GS, Nigam M, Kkhalillulah M. Immediate and long-term results of balloon and surgical closed mitral valvotomy: a randomized comparative study. Am Heart J. $1993 ; 125(4): 1091-4$

6. Reyes VP, Raju BS, Wynne J, Stephenson LW, Raju R, Fromm BS, et al. Percutaneous balloon valvuloplasty compared with open surgical commissurotomy for mitral stenosis. N Engl J Med. 1994;331(15):961-7.

7. Aguiar Filho GB, Lluberas S, Gomes NL, Andrade LFP, Maldonado M, Meneghelo ZM, et al. Evolução muito tardia da valvotomia percutânea por balão na estenose mitral grave. Rev Bras Cardiol Invasiva. 2012;20(3):253-9. 